\title{
Governança hídrica: um estudo de caso em Tangará da Serra, MT, após o desabastecimento de 2016
}

\author{
Water governance: a case study in Tangará da Serra, MT, after water \\ shortage in 2016 \\ Gobernanza del agua: um estudio de caso en tangará da Serra, MT, después de \\ la escasez de 2016 \\ Ana Paula Silva de Andrade ${ }^{1}$ \\ Cleci Grzebieluckas ${ }^{1}$
}

Recebido em: 24/07/2019; revisado e aprovado em: 26/05/2020; aceito em: 17/07/2020 DOI: http://dx.doi.org/10.20435/inter.v22i3.2652

\begin{abstract}
Resumo: Em 2016, um episódio de desabastecimento hídrico em Tangará da Serra, Mato Grosso (MT), desencadeou ações voltadas à conservação ambiental, características de um processo de governança hídrica. O estudo analisou a relação entre o desabastecimento e as ações realizadas, focando os atores envolvidos e seus objetivos. Constitui um estudo de caso, de natureza explicativa e abordagem qualitativa, com instrumento de coleta consistindo em entrevistas baseadas em roteiro semiestruturado, interpretadas a partir da análise de conteúdo. Os relatos evidenciaram a importância do voluntariado e da atuação conjunta com o poder público e demonstraram a preocupação com nova escassez e possíveis conflitos pelo uso da água.
\end{abstract}

Palavras-chave: governança hídrica; voluntariado; conservação ambiental.

Abstract: In 2016, an episode of the water scarcity in Tangará da Serra, Mato Grosso (MT), triggered actions focused on environmental conservation, characteristics of a water governance process. The study aimed to analyze the relationship between the water shortage and the actions performed, focusing on the social actors and their aims. It is a case study, of explanatory nature and qualitative approach, with an instrument of collection consisting of interviews based on a semi-structured script interpreted from the content analysis. The reports highlighted the importance of volunteering and joint action with the public power and showed the concern with new scarcity and possible conflicts for water use..

Keywords: water governance; volunteering; environmental conservation.

Resumen: En 2016, un episodio de escasez del agua en Tangará da Serra, Mato Grosso (MT), desencadenó acciones dirigidas a la conservación del medio ambiente, características de un proceso de gobernanza del agua. El estudio analizó la relación entre la escasez y las acciones realizadas, enfocando los actores involucrados y sus objetivos. Es un estudio de caso, de naturaleza explicativa y enfoque cualitativo, con un instrumento de recolecta que consiste en entrevistas basadas en un guión semiestructurado, interpretado a partir del análisis de contenido. Los informes mostraron la importancia del voluntariado y de la actuación conjunta con el gobierno y destacaron la preocupación por una nueva escasez y los posibles conflitos por el uso del agua. Palabras clave: gobernanza del agua; voluntariado; conservación ambiental.

\section{INTRODUÇÃO}

O acesso à água potável é uma condição intimamente relacionada ao direito à vida, fato que justifica a frequência com a qual questões associadas à escassez de água em nível mundial vêm sendo debatidas, com uma singular preocupação voltada à regulação e otimização do uso dos recursos hídricos, não somente pelos governos, mas especialmente pela sociedade.

A Organização das Nações Unidas (ONU), desde 1966, define a água como um bem jurídico a ser protegido (AITH; ROTHBARTH, 2015), premissa que, ao longo da história, tem ecoado em eventos e documentos, tais como a Declaração de Estocolmo, a Carta de Montreal sobre Água

\footnotetext{
${ }^{1}$ Universidade do Estado de Mato Grosso (UNEMAT), Cuiabá, Mato Grosso, Brasil.
} 
Potável e Saneamento, a Declaração de Dublin e a Rio 92 (AMORIN, 2015; FRATTON; OLIVEIRA, 2016). A Resolução n. 64/292 da Organizações das Nações Unidas [ONU] (2010) ratificou internacionalmente o direito humano à água potável e saneamento, recomendando a estados e organizações que provessem recursos financeiros, capacitação e transferência de tecnologia como garantia para uma disponibilização segura (AITH; ROTHBARTH, 2015; UNITED NATIONS [US], 2010).

A consolidação da questão hídrica na agenda internacional impulsionou a transformação na visão acerca da água, com o status de recurso infindável sendo substituído pela concepção de bem comum e direito humano fundamental. Esta ressignificação do recurso como capital natural implicou a necessidade de ajustamento de seu consumo social (MARTINS, 2013), pelo qual as práticas arraigadas de mau uso e de planejamento tecnocrático e autoritário pudessem ser substituídas (JACOBI, 2008). Assim, abriu-se espaço para mudanças na gestão hídrica, deixando de ser somente uma questão de governo e passando a uma questão de governança (VASCONCELOS et al., 2016).

Enquanto governo trata da possibilidade de diferentes combinações institucionais que favorecem o exercício do poder, a governança é um processo em que novos caminhos teóricos e práticos são propostos e adotados, visando estabelecer uma relação alternativa entre o nível governamental e as demandas sociais para gerir os diferentes interesses (CAMPOS; FRACALANZA, 2010). Em relação à água, fala-se em governança hídrica, uma proposta baseada em instrumentos e princípios que unem as forças do poder público, do setor privado e da participação social (CASTRO, 2002), além de ser fundamentada no paradigma da sustentabilidade (CAMPOS; FRACALANZA, 2010).

Nesse sentido, o conceito de governança hídrica se destaca por pautar-se na construção de agendas participativas por novos atores sociais (multi-stakeholders) e a implementação de políticas públicas, de modo que a gestão passe a considerar novas relações entre sociedade, estado, agentes econômicos, direito, instituições, políticas e ações governamentais (JACOBI et al., 2015).

O conceito de governança hídrica foi idealizado na França, tendo na Lei de Água de 1964 um expoente. Por ela, consolidaram-se os pilares da gestão integrada dos recursos hídricos na escala de bacia hidrográfica e o modelo de parceria público-privada, com serviços locais de água e saneamento, formato exportado para diversos países, inclusive o Brasil, e considerado estável por continuar em vigor e se aprimorando (COLON; RICHARD; ROCHE, 2017).

$\mathrm{Na}$ França, como em outros países industrializados, as redes de água e saneamento remontam ao século XIX e, até a 2a Guerra Mundial, as necessidades de água eram compatíveis com os recursos disponíveis. Ao fim da guerra, com a migração da população das zonas rurais para as cidades e um rápido desenvolvimento industrial, os efeitos do aumento do consumo e da poluição se evidenciaram (COLON; RICHARD; ROCHE, 2017; PEREIRA, 2002). Em 1964, o quadro ainda era de crescimento econômico, mas já se delineava a decisão por uma gestão integrada, que almejava transformar a dinâmica de administração ao reforçar a participação de distintos setores sociais nas instâncias gestoras (MARTINS, 2008).

O processo de descentralização francês valeu-se da criação do Comitê Nacional de Águas, dos Comitês de Bacias e Agências Financeiras de Bacia (mais tarde, Agências de Água), sendo os últimos os responsáveis pela gestão em nível local (MARTINS, 2008), que oportunizou a mudança de paradigma das políticas setoriais fragmentadas para uma gestão da água na escala de território hidrográfico (COLON, 2017).

INTERAÇÕES, Campo Grande, MS, v. 22, n. 3 p. 855-868, jul./set. 2021. 
Segundo a Agência Nacional de Águas (BRASIL, 2017), no Brasil a governança da água se firmou com a Política Nacional de Recursos Hídricos, pela Lei n. 9.433/1997, que conectou a gestão de recursos hídricos com a gestão ambiental pelo Sistema Nacional de Gerenciamento de Recursos Hídricos (SINGREH).

Integram o SINGREH o Conselho Nacional de Recursos Hídricos, os Conselhos de Recursos Hídricos estaduais, os Comitês de Bacia Hidrográfica $(\mathrm{CBH})$, os órgãos de governo cujas competências se relacionem com a gestão de recursos hídricos e as Agências de Água (BRASIL, 1997). Pela lei, esses mecanismos institucionais visam à garantia de participação dos cidadãos e comunidades usuárias de recursos hídricos, por meio da inclusão de seus representantes nos Conselhos e nos $\mathrm{CBH}$.

Nesse caso, a administração dos recursos hídricos pela coparticipação de gestores, usuários e populações locais é justificada, mas só se torna viável com a população mobilizada pela importância da água e do saneamento, atuante na exigência do cumprimento de seus direitos e com potencial crítico para observar seus deveres de não degradar e não desperdiçar o recurso natural (PICCOLI et al., 2016).

Além disso, Backeberg (1997) ressalta que, para que a água seja tratada como bem privado, critérios precisam ser atendidos, em especial os direitos de uso devem ser claramente definidos, com os usuários sendo autorizados a tomar decisões a partir da propriedade. Nesse contexto, a importância da governança hídrica se evidencia, pois equilibra o reconhecimento da água como bem econômico com o conceito de sustentabilidade, legitimando políticas e estratégias que se fundamentam em aspectos tanto econômicos como ambientais e sociais (FRACALANZA; JACOB; ECA, 2013).

Essa conformação se ajusta ao fenômeno observado no município de Tangará da Serra, Mato Grosso (MT), que, após registrar um grave desabastecimento devido à estiagem em 2016, albergou o surgimento de várias mobilizações sociais em relação à conservação de suas águas. Diante disso, este trabalho objetivou analisar a forma como o desabastecimento influenciou a mobilização social e as posteriores ações de governança hídrica no município, por meio da busca pelos atores sociais e organizações envolvidas, descrevendo as propostas apresentadas e os interesses que motivaram tais iniciativas.

Além desta introdução, o trabalho está dividido em três seções, a saber: os procedimentos metodológicos empregados na pesquisa; os resultados e discussão, subdivididos em quatro tópicos, e as considerações finais, com as conclusões do trabalho e sugestão para novos estudos dentro da temática.

\section{PROCEDIMENTOS METODOLÓGICOS}

A pesquisa foi realizada em Tangará da Serra, município localizado no sudoeste de Mato Grosso, a 245 km da capital Cuiabá, que, no ano de 2016 - considerado seco a extremamente seco em grande parte do país e com uma redução de 13\% na precipitação (BRASIL, 2017) -, teve seu regime de chuvas afetado, o que ocasionou um desabastecimento público geral de água.

A pesquisa utilizou como método o estudo de caso, apresentando natureza explicativa e abordagem qualitativa. A principal tendência do estudo de caso é tentar esclarecer um conjunto de decisões: o motivo pelo qual foram tomadas, como foram implementadas e com quais resultados (SCHRAMM, 1971). 
Sua natureza explicativa busca aprofundar o conhecimento da realidade, pelo registro, análise e interpretação dos fenômenos e seus fatores determinantes (COSTA SILVA et al., 2016). Seu viés qualitativo se deu pela contextualização do problema, a partir da classificação das variáveis encontradas, reproduzidas textualmente (GERHARDT; SILVEIRA, 2009).

O instrumento de coleta empregado foi a entrevista, organizada e aplicada a partir de um roteiro semiestruturado elaborado previamente, contendo 8 (oito) perguntas abertas e realizadas entre os dias 9 e 13 de março de 2019, mediante assinatura do Termo de Consentimento Livre e Esclarecido (TCLE), no qual os participantes foram informados sobre a finalidade do estudo, o sigilo sobre suas identidades e por meio do qual autorizaram o uso de suas falas e colocações.

A seleção dos participantes se deu por amostragem intencional, não probabilística, justificada pelo fato de que esta permite ao pesquisador definir o conjunto que subsidiará a análise e interpretação dos dados que considera mais representativos (FONTANELLA et al., 2011). Desse modo, para responder às entrevistas, foram selecionados representantes de instituições que, durante ou após o período de desabastecimento, desenvolveram alguma atividade relacionada à conservação ambiental e hídrica, que tenha sido divulgada na mídia (televisão, jornais, sites e redes sociais).

Para tratamento dos dados obtidos, optou-se pela análise de conteúdo, que examina os relatos, classificando-os em categorias que auxiliam na compreensão do que está por trás dos discursos (HENNIG SILVA; FOSSÁ, 2015).

Por tratar-se de uma pesquisa com abordagem qualitativa baseada em entrevistas, não se objetivou atribuir juízo de valor às respostas recebidas, mas analisá-las dentro do contexto vivenciado pelos participantes. A qualidade das informações obtidas, bem como a frequência das colocações análogas e divergentes, orientou a categorização das respostas dos entrevistados. A pesquisa foi submetida à análise pelo Comitê de Ética em Pesquisa (CEP) da Universidade do Estado de Mato Grosso (UNEMAT) e aprovada sob Parecer n. 2.602.848.

\section{RESULTADOS E DISCUSSÃO}

\subsection{Instituições e propostas}

Destaca-se o voluntariado como força promotora das ações relatadas, uma vez que todos os entrevistados (cujas falas serão identificadas pela letra E, seguida pelo número de ordem da entrevista) atuaram voluntariamente nos projetos, mesmo aqueles promovidos por empresas privadas. Ações voluntárias voltam-se à cidadania, com a realização de trabalhos de caráter educativo, cultural e de lazer, em que o meio ambiente passou também a figurar como compromisso social a ser observado (BARELI; LIMA, 2010). A atuação das entidades e dos voluntários em questões ambientais auxilia, ainda, na construção de uma imagem de atenção para com o meio ambiente, promovendo as iniciativas de forma positiva.

Nesse âmbito, todos os entrevistados ressaltaram ter buscado articular propostas em prol da sociedade, expondo a preocupação com o coletivo, que se evidencia em colocações como:

E além de ajudar a sociedade [...] mostrar para essas pessoas a importância que tem a gente fazer as ações ambientais. (E1).

A gente pensou em alguma coisa que a gente precisa [...] a gente pensou no bem comum de todo mundo [...] no bem comum da cidade de Tangará. (E2). 
[...] e a partir dali nasceu em nós o desejo de discutir de maneira ampla [...] o resultado daqueles debates culminou na Carta [...] que foi um instrumento feito a várias mãos. (E5).

Das seis propostas descritas, três foram voltadas ao plantio de árvores em áreas consideradas de interesse e autorizadas pela prefeitura municipal (Estação de Tratamento de Água [ETA] e margens de um córrego), uma baseou-se na elaboração de um documento com propostas voltadas à conservação das águas, uma constitui lei sobre a proteção de nascentes, e a última corresponde a ações realizadas pelo CBH do município, apresentadas no Quadro 1.

Quadro 1 - Descrição das propostas ambientais pós-desabastecimento

\begin{tabular}{|c|c|c|c|c|}
\hline INSTITUIÇÃO & PROPOSTA & DURAÇÃO & PARTICIPANTES & LOCAL \\
\hline $\begin{array}{l}\text { Cooperativa } \\
\text { Médica }\end{array}$ & Plantio de 400 mudas & 5 anos & $\begin{array}{c}\text { Colaboradores, } \\
\text { cooperados e famílias }\end{array}$ & ETA \\
\hline $\begin{array}{l}\text { Entidade } \\
\text { Religiosa }\end{array}$ & $\begin{array}{l}\text { Plantio (de } 50 \text { a } 90 \text { mudas } \\
\text { por mês) a cada batizado } \\
\text { realizado }\end{array}$ & 2 anos & $\begin{array}{c}\text { Organizadores e } \\
\text { famílias dos batizados }\end{array}$ & ETA \\
\hline Clube de Serviços & Plantio de 350 mudas & Indefinida & \begin{tabular}{|c|} 
Organizadores e \\
participantes do clube \\
\end{tabular} & $\begin{array}{l}\text { Córrego da } \\
\text { cidade }\end{array}$ \\
\hline $\begin{array}{l}\text { Entidade de } \\
\text { Classe }\end{array}$ & $\begin{array}{c}\text { Documento com propostas } \\
\text { técnicas apresentado ao } \\
\text { poder público }\end{array}$ & Encerrada & \begin{tabular}{|c|} 
Comunidade e \\
pessoas com \\
conhecimento técnico \\
reconhecido
\end{tabular} & $\begin{array}{l}\text { Âmbito } \\
\text { municipal }\end{array}$ \\
\hline $\begin{array}{l}\text { Câmara } \\
\text { Municipal }\end{array}$ & $\begin{array}{c}\text { Lei sobre recuperação } \\
\text { de nascentes situadas na } \\
\text { microbacia dos rios Queima } \\
\text { Pé e Ararão }\end{array}$ & Indefinida & $\begin{array}{c}\text { Órgãos e entidades, } \\
\text { públicas ou privadas, } \\
\text { e pessoas físicas ou } \\
\text { jurídicas }\end{array}$ & $\begin{array}{l}\text { Âmbito } \\
\text { municipal }\end{array}$ \\
\hline $\begin{array}{l}\text { Comitê de Bacia } \\
\text { Hidrográfica }\end{array}$ & $\begin{array}{l}\text { Recuperação dos rios } \\
\text { Queima-Pé e Ararão; } \\
\text { curso de adequação de } \\
\text { topografia de estradas }\end{array}$ & Indefinida & $\begin{array}{l}\text { Entidades públicas } \\
\text { e privadas e } \\
\text { representantes da } \\
\text { sociedade }\end{array}$ & $\begin{array}{c}\text { Âmbito } \\
\text { intermunicipal }\end{array}$ \\
\hline
\end{tabular}

Fonte: Dados da pesquisa, 2019.

Especificamente sobre a questão da escassez de água no planeta, houve, nos últimos anos, grande divulgação de publicações de alerta, como as pesquisas sobre mudanças climáticas que influenciam nas chuvas e outras que têm sido registradas e divulgadas pelas mídias nacional e internacional, sendo frequente nas falas a correspondência entre a falta de água ocorrida no município em 2016 e as ações realizadas:

Em 2016 a gente sofreu aquela falta d'água, aquela coisa toda, ficou todo mundo muito abalado, foi muito difícil [...] então escolhemos pra fazer em 2017 um reflorestamento. (E1).

Vamos plantar árvores [...] em 2016 teve aquela grande falta de água, onde entrou em estado de calamidade, né, que deu, muitas pessoas comprando água, muitas pessoas sem beber, não tinham água pra beber. (E2).

Até porque a nossa cidade sofreu diretamente alguns anos atrás com a falta d'água [...] então a gente quis unir a importância que tem manter a preservação. (E3).

[...] então, naquela loucura de falta de água e todo mundo com caixa d'água, então nós fizemos aquele evento [...]. (E5). 
A ameaça de novos episódios de escassez e a possibilidade de ter que conviver com ela permanentemente trouxeram inquietação à população e direcionaram seu olhar para as áreas vulneráveis do município e sobre o que poderia ser feito para evitar novo desabastecimento, o que se traduziu, no caso, por ações como o plantio de árvores em áreas de risco, sugestões técnicas feitas com a colaboração da sociedade para melhoria de infraestrutura e elaboração de leis visando à conservação ambiental. Assim, a noção da privação ressaltou o que é essencial para sobrevivência e sublinhou a importância da manutenção dos recursos hídricos e da pertinência da mobilização coletiva.

\subsection{Mobilização da Sociedade Civil}

A mobilização é caracterizada pelo decidir e agir de um grupo de pessoas, uma comunidade ou uma sociedade acerca de um objetivo comum, em busca de resultados definidos e desejados pela coletividade (TORO; WERNECK, 1996). Essa transformação, no entanto, não se restringe à simples tomada de consciência, mas ao seu desenvolvimento crítico, e depende da disseminação do conhecimento e da interação entre a realidade humana e o ambiente.

Essa concepção se faz presente nas falas dos entrevistados, quando abordam o potencial de suas ações, apontando como fator positivo a disseminação das práticas e o envolvimento das pessoas, enquanto família, e, principalmente, das crianças:

Nós mobilizamos cem voluntários, esses cem voluntários levam essa vivência pra dentro da família [...], imagina só, criança! (E1).

Toda mãe, quando a gente conversa sobre o filho que vai ganhar uma árvore, ela fala, acha assim, muito legal [...] que ele vai poder cuidar da árvore dele. (E2).

Ele [o projeto] foi criado, na verdade, para passar consciência para as crianças [...] a importância de... do cuidado com o meio ambiente. (E3).

Um ponto positivo foi a disseminação de conhecimento [...]. (E5).

A opção por atividades como a arborização oportuniza uma experiência prática (e, muitas vezes, nova para muitos), que permite o contato com o ambiente em recuperação, desde as etapas iniciais, e oportuniza um sentimento de cuidado e responsabilidade com o meio ambiente. Nesse sentido, a participação de crianças e jovens tem papel preponderante, pois estes representam as novas gerações que podem adquirir novos hábitos e internalizar ações que garantam a sustentabilidade no futuro.

A concepção da arborização como mitigadora dos efeitos da escassez hídrica, atuando na conservação das águas, foi uma correlação interessante encontrada, pois, como 2016 foi um ano de maior estiagem, tal fato foi bastante divulgado na época e pode ter influenciado a promoção da importância do reflorestamento. Além disso, as decisões relativas ao uso do solo de um lugar podem ter consequências significativas para os recursos hídricos de outras localidades, o que ratifica a disposição em reflorestar presente entre as propostas dos entrevistados.

Embora a arborização seja uma atividade considerada simples, os entrevistados assumiram que as tarefas a que se propuseram demandaram mais que boa vontade, por existirem complexidades relacionadas ao trato ambiental das quais só se deram conta ao partir para a prática.

Dos seis entrevistados, três afirmaram ter recorrido a empresas ou pessoas que detinham conhecimento técnico para aconselhamento sobre os melhores procedimentos nas ações:

INTERAÇÕES, Campo Grande, MS, v. 22, n. 3 p. 855-868, jul./set. 2021. 
E a gente achou que seria só, ah, vamos lá e vamos plantar as mudinhas [...]. Nosso corpo de voluntários não estava qualificado para desenvolver o trabalho [risos], então a gente preferiu fazer uma parceria [...]. (E1).

Nós temos o nosso grupo, alguns engenheiros agrônomos [...] a gente aposta no conhecimento técnico que eles têm e eles nos guiam, digamos, tecnicamente. (E3).

[...] de entes e de pessoas com conhecimento distinto, porém correlato, quando se tratava de meio ambiente e preservação das águas. (E5).

Nesse despertar sobre a necessidade de conhecimento técnico que a experiência trouxe aos entrevistados, a busca por orientação revela ainda preocupação com o êxito e a continuidade dos empreendimentos. Dos seis projetos instituídos, foi reportado que cinco deles têm previsão de continuidade nos locais inicialmente idealizados, com dois prevendo a expansão em momentos futuros para outros locais que necessitem de intervenção, uma mostra do sucesso de sua implantação:

Terminando a ETA, a gente tem, sim, a gente vai passar pra outros lugares [...] o segundo [...] é o Parque Figueira. (E2).

Tem planos de utilizar esse mesmo formato em outros lugares, sim, pra pegar outra área, fazer a mesma coisa, devolver pra sociedade no mesmo formato. (E3).

Tá no plano também, dar palestras nos colégios, né, de cada um da nossa área vai dar plano de palestra e de divulgação, na Semana do Meio Ambiente. (E4).

Apenas um entrevistado afirmou não ter ocorrido continuidade de sua proposta, que consistiu no debate público, elaboração e entrega de um documento técnico com sugestões de soluções embasadas em intervenções de engenharia, recuperação ambiental e cobrança pelo uso da água aos órgãos competentes, conforme explicitado na fala:

Não, feito aquele movimento, né, entregamos o resultado daquele movimento para o chefe do município, o prefeito municipal [...] não sabemos se algo daquilo foi aproveitado, né, de maneira efetiva, se alguma ideia foi colocada em prática. (E5).

Essa proposta em específico representa o conceito de governança hídrica, pois, ao identificar o problema gerado pelo desabastecimento aos cidadãos de modo geral, um determinado setor da sociedade idealizou e promoveu um evento aberto à participação de todos, mas com a presença especialmente solicitada de pessoas de conhecimento reconhecido na área ambiental e de engenharia, para juntos discutirem propostas e alternativas objetivando atenuar a situação de emergência na qual o município se encontrava, em curto e longo prazo.

No entanto, mesmo tendo a ciência e a vivência da escassez, onde raramente ela ocorre, promovida uma inclinação inicial para discutir a situação e suas possíveis soluções, a descontinuidade no acompanhamento da proposta desenvolvida revelou desinteresse na sua tramitação e, principalmente, na cobrança pela sua implementação.

Isso posto, para que a instituição de uma governança hídrica sólida funcione de modo satisfatório e atue a favor da colaboração entre gestores, usuários e populações locais na administração dos recursos hídricos, é necessário que os atores sociais estejam bem informados e sejam proativos, a fim de promover a mobilização na defesa de seus interesses e de um desenvolvimento sustentável com preservação ambiental, de forma constante e ativa.

Embora alguns requisitos para um processo efetivo de governança hídrica tenham sido observados, como a propositura e o desenvolvimento das ações, evidenciou-se nas entrevistas o 
desconhecimento sobre o termo. Dos seis entrevistados, dois responderam não conhecê-lo e dois afirmaram ter ouvido falar, mas de modo superficial. Um entrevistado fez a associação do termo com a governança corporativa, que não faz correspondência direta com a governança hídrica.

Apenas um dos entrevistados afirmou saber do que se trata a governança hídrica, inclusive enfatizando que, em sua instituição, ela não está configurada da forma como deveria ser, por haver disputas internas de poder:

Já! Já, já ouvi falar e... inclusive tá em conflitos lá dentro, as coisas, não estão com... não tá redondinho lá, né, como é pra ser. Tem, tem jogo de interesse, né? (E4).

Em relação a isso, faz-se relevante compreender que as intervenções no meio ambiente sofrem influência direta da forma como as decisões políticas, os direcionamentos econômicos e as organizações sociais são determinados, e, quando há um interesse individual que sobrepuja o coletivo, incorre-se fatalmente no risco de conflitos, especialmente quando a atuação ambiental é condicionada a exercícios de poder e manipulação, conforme levantado pelo entrevistado.

\subsection{Uso da água e conflitos}

As variadas finalidades dos recursos hídricos são denominadas de usos múltiplos e podem ser voltadas ao abastecimento doméstico, público e privado, uso industrial, turismo, transporte, dessedentação de rebanhos, entre outros (NASCIMENTO, 2017), e, em razão de fatores como desigualdade na distribuição geográfica e diferentes padrões de consumo, podem se tornar fontes de sérios conflitos.

No período do desabastecimento em Tangará da Serra, Siebert (2016) analisou que o fato de o município se localizar em região abundante em água doce não evitou um problema de abastecimento público, que afetou o comércio e a produção agropecuária (frigoríficos de bovinos e aves) e pequenos produtores que dependem da água da bacia do Rio Queima-Pé, principal rio do município, além do uso da água para geração de eletricidade que também existe no município.

Um dos projetos para construção de Pequena Central Hidrelétrica em tramitação prevê a utilização do Rio Formoso, cuja área de abrangência engloba quatro territórios indígenas homologados - Estivadinho, Paresí, Figueiras e Rio Formoso -, todos localizados no município, que possui mais da metade de sua área formada por terras indígenas homologadas (CIRCUITO MATO GROSSO, 2018).

Segundo Sakamoto (2010), mesmo que os empreendimentos se encontrem temporariamente suspensos, devido justamente à ausência de uma exigência legal chamada Plano Básico Ambiental do Componente Indígena (PBA-CI), há ainda a questão da exploração comercial de soja feita em lavouras mecanizadas dentro das reservas pelos próprios povos indígenas, destacando-se os Paresí (com 15.500 hectares já ocupados, divididos em 17 lavouras não contínuas, computadas em 2010), que optaram por investir e fazer parcerias com grandes fazendeiros, o que tem suscitado uma complexa discussão jurídica sobre a legalidade dos acordos.

Nesse âmbito, o impacto socioeconômico da escassez define o agravamento dos conflitos territoriais pelo uso da água (JACOBI et al., 2015), indispondo os pequenos produtores com a agroindústria, a preservação ambiental com atividades de produção e os processos de urbanização com os outros usos múltiplos dos recursos hídricos (NASCIMENTO, 2017). Essa inquietação perante a possibilidade de enfrentamento de nova situação de desabastecimento e, por consequência, os conflitos por ela desencadeados estão registrados na fala de um dos entrevistados: 
Porque é múltiplo uso hoje, não tem como eu proibir alguém de utilizar esta ou aquela água quando tem autorização e outorga [...]. Nós vamos ter brigas, guerras futuras aí por conta da água. (E6).

Diante disso, pode-se notar que o município reúne todos os pré-requisitos que contribuem para o surgimento de conflitos dentro de seus limites. De um lado, grandes projetos de produtores e investidores, com vantagens econômicas como aumento de arrecadação e geração de emprego no município; e, por outro, habitantes de tempos imemoriais da região, que exigem a autonomia quanto ao uso de suas terras e, no cerne da discussão, ainda que muitas vezes subestimada, a questão da utilização e proteção dos recursos ambientais, indispensáveis para a realização destas atividades.

\subsection{Poder público e as ações}

Em relação ao tratamento dispensado às ações ambientais pelo poder público, a prefeitura foi um órgão bastante citado durante as entrevistas, desempenhando papel ativo na implementação das ações, conforme atestam as falas a seguir:

Protocolamos nosso projeto na prefeitura [...] a prefeitura super deu abertura. (E1).

A prefeitura, ela vai passar várias áreas que a gente vai poder plantar. (E2).

A gente conseguiu com a prefeitura, em parceria com a prefeitura, eles nos deram autorização de recuperar uma área nas margens do córrego [...]. (E3).

Eu já dei um curso aqui [...] de treinamento de adaptação da topografia de estradas [...] esse é um plano que tá sendo solicitado pela prefeitura, já me pediram novo treinamento. (E4).

Sua disposição favorável se verifica mais claramente em relação à designação da área pública da ETA como espaço para desenvolvimento de projetos ambientais. A situação de degradação ambiental no entorno da estação é de conhecimento geral, devido à grande divulgação feita na mídia à época e também por ser um local público de fácil acesso, porém a prefeitura não se furtou a indicá-lo para espaço de atividades de cunho ambiental, reconhecendo a necessidade de intervenção, segundo pontuado pelos entrevistados nas seguintes colocações:

A gente escolheu uma área lá na ETA [...]. Por conta da falta d'água de 2016, eles tiveram que desmatar um pedação [...] pra poder ampliar o reservatório de água do município. Então a gente quis minimizar uma pequena parcela daquilo que foi desmatado. (E1).

Mas as nossas represas [...] ela não tem esse cinturão verde [...]. Foi onde a gente pensou em ir lá e reflorestar esse cinturão verde, na ETA. (E2).

A união do governo e das iniciativas sociais por todo o mundo, além de constituir um dos objetivos da governança ambiental, tem feito diferença no sentido de obter maior eficiência na regulação e evolução das comunidades.

Existe uma conjuntura de requisitos que instam o Estado a incentivar as parcerias com o voluntariado, seja pelo fato da promoção dos serviços que fortalecem o vínculo com a sociedade, que assume diretamente parcela relevante do espaço e poder público, seja pelo suprimento das deficiências ainda percebidas em seu aparelhamento (MELLO, 2014).

A percepção dessas deficiências transparece na fala de uma das entrevistadas, para a qual o cerne do trabalho de sua instituição é cobrir as lacunas deixadas pelo poder público na administração das questões sociais: 
[...] é uma organização de líderes [...] que unidos trabalham... para sanar algumas mazelas do mundo [...] a gente tá aonde as pessoas que deveriam chegar não conseguem, a gente faz esse tipo de serviço. (E3).

A ineficiência do Estado em otimizar a aplicação dos recursos públicos com vista à máxima concretização de direitos fundamentais ainda prevalece no caso brasileiro, que tende a ser reprodutor e não erradicador de desigualdades e onde as instâncias de participação e deliberação popular ainda são pouco ou mal utilizadas, não conseguindo assegurar a efetividade dos direitos sociais fundamentais (MELLO, 2014).

Tal condição é asseverada pela colocação de um entrevistado, ao discorrer sobre uma nova possibilidade de desabastecimento e sua relação com a manutenção e proteção de nascentes:

Pela identificação, nós temos mais de cem nascentes aqui no entorno da microbacia do Rio Queima-Pé, e o poder público sozinho não vai conseguir fazer isso, aliás, não faz. Nós não temos nenhum registro de recuperação de nascentes. (E6).

Outra colocação feita por um entrevistado coloca em xeque o interesse dos poderes municipais em participar da formação do Comitê de Bacia Hidrográfica:

Mas há pouca participação [...] tamo insistindo, né, eles participavam pouco, começou a retirar, as mudanças políticas, houve desvios, né? Não houve interesse na hora de inscrever pro Ministério Público. (E4).

Embora as demandas sociais impliquem na articulação e interação de diferentes setores, a fragmentação é um aspecto comum nas políticas públicas no Brasil, os processos de governança dependem da transparência e do acesso às informações, pois essas oportunizam a inclusão, participação e capacidade de resposta dos interessados, auxiliando-os a se apropriar da problemática, para então se engajar e cooperar em direção às ações conjuntas de mitigação e solução de impasses (MELLO, 2014; JACOBI et al., 2015).

No entanto, em um cenário de governança hídrica, apesar de o governo, de modo geral, constituir um elemento-chave no processo de integração, graças a sua qualidade de regulador, as responsabilidades passam a ser divididas de maneira igualitária entre este, a sociedade e as organizações, não cabendo somente a uma parte os encargos das ações, mas a todos de modo conjunto e colaborativo.

\section{CONSIDERAÇÕES FINAIS}

A análise das entrevistas sugere que, diante da escassez de água, a vivência do desabastecimento e de seus efeitos suscitaram a mobilização do voluntariado de vários setores, com a propositura de ações ambientais e a preocupação com a continuidade dos projetos iniciados. As propostas visaram não apenas à recuperação ambiental, mas à inclusão de agentes, especialmente crianças, que pudessem assimilar e disseminar a importância da conservação dos recursos hídricos e, assim, alcançar maior número de pessoas de seus relacionamentos.

Pôde-se notar que já existe uma predisposição à formação de grupos que tomam para si a responsabilidade de atuar na frente ambiental no município, apesar de persistir um sentimento de que tal incumbência seja unicamente do poder público, o que é incompatível com a proposta de descentralização, participação e integração que caracteriza a governança hídrica e que corrobora com o resultado encontrado na pesquisa de desconhecimento sobre o termo. 
O apoio do poder público municipal foi essencial para a concretização das ações e, ao contrário do que é muitas vezes visto, de ações ambientais serem realizadas, mas acabarem esquecidas pelos órgãos normativos e institucionais, as iniciativas estão em andamento e há previsão de continuidade dos projetos dentro do município.

A crise hídrica, vista pelo legado positivo, promoveu a parceria entre a sociedade civil e o poder público, pautada na revitalização dos recursos hídricos, por meio do engajamento de vários grupos sociais. Essa mobilização, ainda que de maneira não intencional, delineia-se em grande parte como um processo de governança hídrica no município, que pode se expandir, considerando a existência do Comitê de Bacia Hidrográfica, dependendo exclusivamente do interesse dos envolvidos.

Sugere-se que sejam realizados levantamentos de outras propostas com foco ambiental, com maior abrangência temporal e estudos sobre a variação no padrão de consumo de água antes e após o período de desabastecimento no município.

\section{REFERÊNCIAS}

AITH, F. M. A.; ROTHBARTH, R. O estatuto jurídico das águas no Brasil. Estudos Avançados, São Paulo, v. 29, n. 84, p. 163-77, 2015. Disponível em: http://www.scielo.br/ scielo.php?script=sci_ arttext\&pid=S0103-4014201500020 0163\&Ing=en\&nrm=iso. Acesso em: 24 jan. 2019.

AMORIN, J. A. A. Direito das águas: o regime jurídico da Água Doce no Direito Internacional e no Direito Brasileiro. São Paulo: Atlas, 2015.

BACKEBERG, G. R. Water institutions, markets and decentralised resource management: prospects for innovative policy reforms in irrigated agriculture. Agrekon, South Africa, v. 36, n. 4, p. 350-84, 1997. Disponível em: https://ageconsearch.umn.edu/ record/54433/files/01_backe\%20-\%20december\%20 1997.pdf. Acesso em: 5 mar. 2019.

BARELI, P. LIMA, A. A importância social do desenvolvimento do trabalho voluntário. Revista de Ciências Gerenciais, Campinas, v. 14, n. 20, p. 173-84, 2010. Disponível em: http://revista.pgsskroton.com.br/ index.php/rcger/article/view/2280/2179. Acesso em: 17 mar. 2019.

BRASIL. Ministério de Desenvolvimento Regional. Agência Nacional de Águas [ANA]. Conjuntura dos recursos hídricos no Brasil: informe 2017. ANA: Brasília-DF, 2017. Disponível em: http://www.snirh.gov. $\mathrm{br} /$ portal/snirh/ centrais-de-conteudos/conjuntura-dos-recursos-hidricos/conj2017_rel-1.pdf. Acesso em: 15 mar. 2019.

BRASIL. Lei Federal n. 9.433, de 8 de janeiro de 1997. Institui a Política Nacional de Recursos Hídricos, cria o Sistema Nacional de Gerenciamento de Recursos Hídricos, regulamenta o inciso XIX do art. 21 da Constituição Federal, e altera o art. 1o da Lei n. 8.001, de 13 de março de 1990, que modificou a Lei n. 7.990, de 28 de dezembro de 1989. Brasília-DF, 1997. Disponível em: http://www.planalto.gov.br/ccivil_03/ Leis/L9433.htm. Acesso em: 15 mar. 2019.

CAMPOS, V. N. O.; FRACALANZA, A. P. Governança das águas no Brasil: conflitos pela apropriação da água e a busca da integração como consenso. Ambiente \& Sociedade, Campinas, v. 13, n. 2, p. 365-82, 2010. Disponível em: http://www.scielo.br/pdf/ asoc/v13n2/v13n2a10.pdf. Acesso em: 6 mar. 2019.

CASTRO, J. E. La construcción de nuevas incertidumbres, tecnocracia y la política de la desigualdad: el caso de la gestión de los recursos hídricos. Revista Iberoamericana de Ciencias, Tecnología, Sociedad e Innovación, España, v. 2, n. 2, [n.p.], 2002. Disponível em: https://www.oei.es/historico/revistactsi/ numero2/esteban.htm. Acesso em: 6 mar. 2019. 
CIRCUITO MATO GROSSO. Hidrelétricas do rio Formoso estão paralisadas por impacto em terras indígenas. Circuito Mato Grosso, Mato Grosso, 2018. Disponível em: http://circuitomt.com.br/editorias/ juridico/127248-licenciamento-para-pequenas-hidreletricas-no-rio-formoso-sao-suspensas-.html. Acesso em: 28 abr. 2019.

COLON, M.; RICHARD, S.; ROCHE, P. A. The evolution of water governance in France from the 1960s: disputes as major drivers for radical changes within a consensual framework. Water International, France, v. 43, n. 1, p. 109-32, 2017. Disponível em: https://www.tandfonline.com/ doi/full/10.1080/02508060.2 018.1403013?scroll=top\&needAccess=true. Acesso em: 6 mar. 2019.

COSTA SILVA, C. M.; CARVALHO, J. R. M.; LUZ, J. R. M.; ALBUQUERQUE, L. S.; OlIVEIRA, P. S. Análise das metodologias e técnicas de pesquisas sobre os ativos intangíveis nos eventos da área contábil no Brasil. Revista eletrônica do Alto Vale do Itajaí (Reavi), Ibirama , v. 5, n. 7, p. 37-57, 2016. Disponível em: http:// www.revistas.udesc.br/index.php/ reavi/article/view/2316419005072016037/5567. Acesso em: 3 mar. 2019.

FONTANELLA, B. J. B.; LUCHESI, B. M.; SAIDEL, M. G. B.; RICAS, J.; TURATO, E. R.; MELO, D. G. Amostragem em pesquisas qualitativas: proposta de procedimentos para constatar saturação teórica. Cadernos de Saúde Pública, Rio de Janeiro, v. 27, n. 2, p. 388-94, 2011. Disponível em: http://www.scielo.br/scielo. php?script=sci_arttext\&pid=S0102-311X20110 00200020\&lng=en\&nrm=iso\&tlng=pt. Acesso em: 18 mar. 2019.

FRACALANZA, A. P.; JACOB, A. M.; ECA, R. F. Justiça ambiental e práticas de governança da água: (re) introduzindo questões de igualdade na agenda. Ambiente \& Sociedade, São Paulo, v. 16, n. 1, p. 19-38, 2013. Disponível em: http://www.scielo.br/pdf/ asoc/v16n1/a03v16n1.pdf. Acesso em: 3 mar. 2019.

FRATTON, E. F.; OLIVEIRA, A. C. O reconhecimento do direito à água potável como direito humano fundamental no direito internacional público. In: SEMINÁRIO INTERNACIONAL DEMANDAS SOCIAIS E POLÍTICAS PÚBLICAS NA SOCIEDADE CONTEMPORÂNEA, 13.; MOSTRA INTERNACIONAL DE TRABALHOS CIENTífICOS, 9., 24-25 out. 2016, Santa Cruz do Sul. Anais [...]. Santa Cruz do Sul, 2019. Disponível em: https://online.unisc.br/acadnet/anais/index.php/sidspp/article/view/16031/3921. Acesso em: 4 mar. 2019.

GERHARDT, T. E.; SILVEIRA, D. T. (Org.). Métodos de pesquisa. 1. ed. Porto Alegre: Editora UFRGS, 2009. Disponível em: http://www.ufrgs.br/cursopgdr/downloadsSerie/derad005.pdf. Acesso em: 12 maio 2018.

HENNIG SILVA, A.; FOSSÁ, M. I. T. Análise de conteúdo: exemplo de aplicação da técnica para análise de dados qualitativos. Qualitas Revista Eletrônica, Campina Grande, v. 17. n. 1, p. 1-14, 2015. Disponível em: http://revista.uepb.edu.br/index.php/qualitas/article/view/\%2021 13/1403. Acesso em: 4 mar. 2019.

JACOBI, P. R. Governança da água e aprendizagem social no Brasil. Sociedad Hoy, Concepción, n. 15, p. 2544, 2008. Disponível em: http://www.redalyc.org/articulo.oa?id=90217091003. Acesso em: 12 jan. 2019.

JACOBI, P. R.; CIBIM, J.; LEÃO, R. S. Crise hídrica na macrometrópole paulista e respostas da sociedade civil. Estudos Avançados, São Paulo, v. 29, n. 84, p. 27-42, 2015. Disponível em: http://www.scielo.br/ scielo.php?script=sci_arttext\&pid=S0103-40142015000200027. Acesso em: 13 jan. 2019.

MARTINS, R. C. A construção social da economia política da água. Sociologia, Problemas e Práticas, Oeiras, n. 73, p. 111-30, 2013. Disponível em: http://www.scielo.mec.pt/scielo. php?script=sci_arttext\& pid=S0873-652920130003000 06\&lng=pt\&nrm=iso. Acesso em: 24 fev. 2019.

MARTINS, R. C. Sociologia da governança francesa das águas. Revista Brasileira de Ciências Sociais, São Paulo, v. 23, n. 67, p. 83-100, 2008. Disponível em: http://www.scielo.br/scielo.php? script=sci_arttext\& pid=S0102-69092008000200007\& Ing=en\&nrm=iso\&tlng=pt. Acesso em: 1o jan. 2019. 
MELLO, J. A. A. B. O Terceiro setor na prestação de serviços públicos: com o controle apropriado, por que não? In: BIRNFIELD, L. F. H.; XAVIER, L. N.; SANTOS, G. F. (Org.). Direito e Administração Pública III, 1. ed. Florianópolis: CONPEDI, 2014. p. 418-47. Disponível em: http://www.publicadireito.com.br/ artigos/?cod=f4e4b6af8c2d1b0e. Acesso em: 19 mar. 2019.

NASCIMENTO, F. Categorização de usos múltiplos dos recursos hídricos e problemas ambientais. Revista da Associação Nacional de Pós-graduação e Pesquisa em Geografia: ANPEGE, [s.I.], v. 7, n. 1, p. 81-97, 2017. Disponível em: http://ojs.ufgd.edu.br/index.php/anpege/article/view/6555/3555. Acesso em: 18 mar. 2019.

PEREIRA, J. S. A. Cobrança pelo uso da água como instrumento de gestão dos recursos hídricos: da experiência francesa à prática brasileira. 2002. 110 f. Dissertação (Mestrado em Engenharia Civil) Universidade Federal do Rio Grande do Sul, Porto Alegre, RS, 2002. Disponível em: https://lume.ufrgs. br/bitstream/handle/10183/1663/000354726. pdf?sequence= 1\&isAllowed=y. Acesso em: 6 mar. 2019.

PICCOLI, A. S.; KLIGERMAN, D. C.; COHEN, S. C.; ASSUMPCÃO, R. F. Environmental education as a social mobilization strategy to face water scarcity. Ciência \& Saúde Coletiva, Rio de Janeiro, v. 21, n. 3, p. 797808, 2016. Disponível em: http://www.scielo.br/scielo.php?pid=S1413-81232016000300797\&script=sci_ abstract\&tlng=pt. Acesso em: 22 jan. 2019.

SAKAMOTO, L. Impactos da soja sobre terras indígenas no estado do Mato Grosso. [S.I.]: Centro de Monitoramento de Agrocombustíveis; ONG Repórter Brasil, 2010. Disponível em: https://reporterbrasil. org.br/documentos/indigenas_soja_MT.pdf. Acesso em: 20 jan. 2019.

SCHRAMM, W. Notes on case studies of instructional media projects. California: Stanford University, 1971. (Working paper, 092145). Disponível em:

https://files.eric.ed.gov/fulltext/ED092145.pdf. Acesso em: 21 fev. 2019.

SIEBERT, D. Escassez de água em Tangará da Serra: uma tragédia anunciada. Campo Grande News, Campo Grande 2016. Disponível em: . Acesso em: 18 mar. 2019.

TORO, J. B.; WERNECK, N. M. D. Mobilização social: um modo de construir a democracia e a participação. Brasília-DF: MMA; ABEAS; UNICEF, 1996. (Comunicação e Mobilização social, 2). Disponível em: https:// books.google.com.br/books?id=01DdbHnbllC\&printsec=frontcover \&hl=ptBR\&source=gbs_ge_summar y_r\&cad=0\#v=onepage\&q\&f=false. Acesso em: 18 mar. 2019.

ORGANIZAÇÕES DAS NAÇÕES UNIDAS [ONU]. Resolution adopted by the General Assembly: the human right to water and sanitation, 28 jul. 2010. [S. I]: ONU, 2010. (Document A/RES/64/292). Disponível em: http://www.un.org/en/ga/search/view_doc.asp?symbol=A/RES/64/ 292. Acesso em: 24 fev. 2019.

VASCONCELOS, D.; GONDIM, N.; HORDONES, P. A.; SILVA, A. C.; BARROS, M. R. Governança da água no Brasil: uma contribuição bibliométrica. HOLOS, Natal, ano 32, v. 8, p. 147-55, 2016. Disponível em: http:// www.redalyc.org/articulo.oa?id= 481554883014. Acesso em: 21 jan. 2019.

\section{Sobre as autoras:}

Ana Paula Silva de Andrade: Mestranda em Ambiente e Sistemas de Produção Agrícola na Universidade do Estado de Mato Grosso (UNEMAT). Pós-graduada em Gestão em Saúde e Meio Ambiente pela Faculdade Afirmativo (FAFI). Bacharel e licenciada em Ciências Biológicas pela UNEMAT. E-mail: anapsakm@ @otmail.com, Orcid: http://orcid.org/0000-0001-5017-8526

Cleci Grzebieluckas: Doutora em Engenharia de Produção pela Universidade Federal de Santa Catarina (UFSC). Mestre em Administração de Empresas pela Universidade do Vale do Itajaí 
(UNIVALI). Bacharel em Ciências Contábeis pela Universidade do Estado de Mato Grosso (UNEMAT). Professora adjunta na UNEMAT, Campus de Tangará da Serra, MT. E-mail: cleci@unemat.br, Orcid: http://orcid.org/0000-0001-9786-9607 